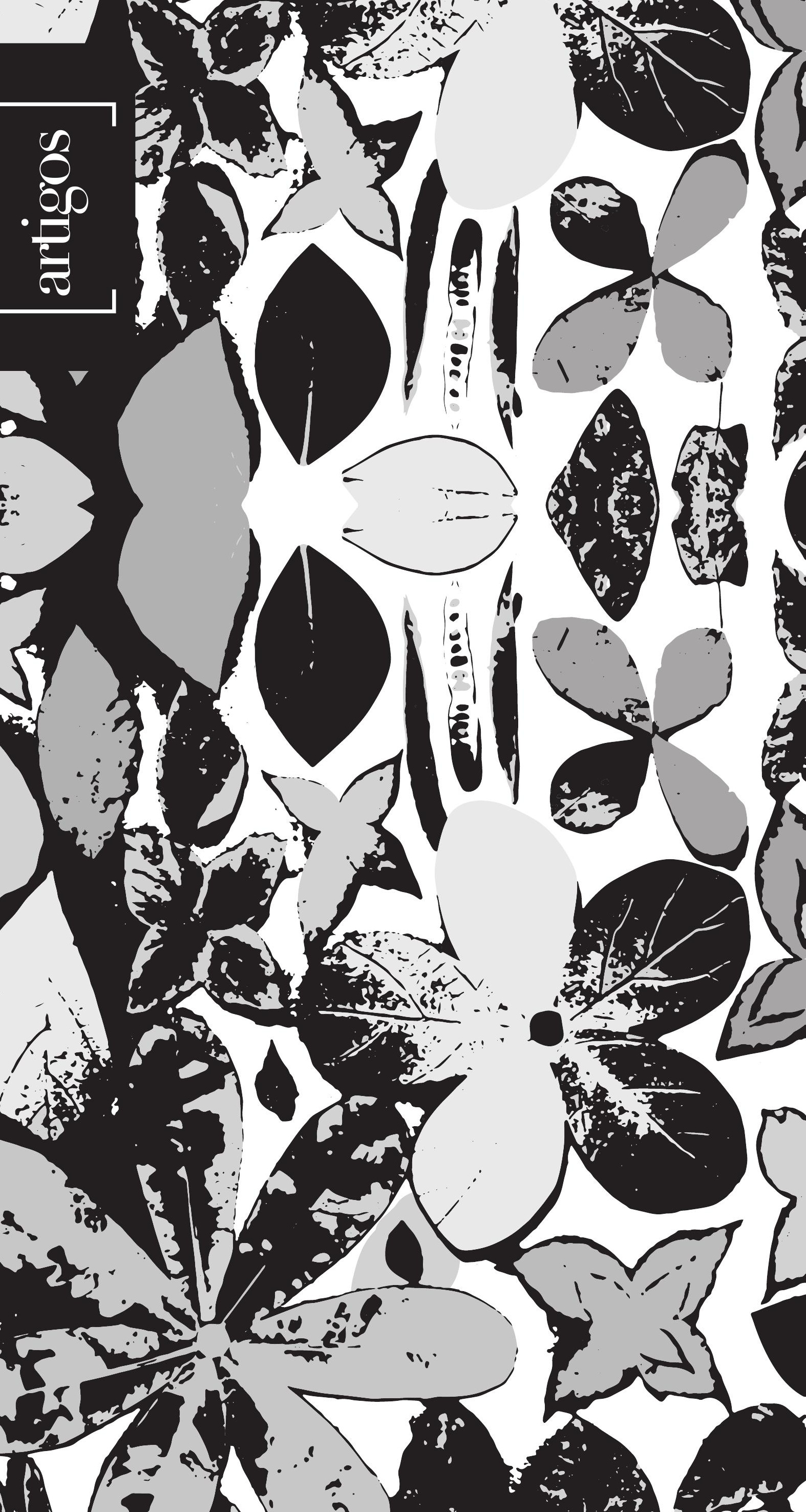




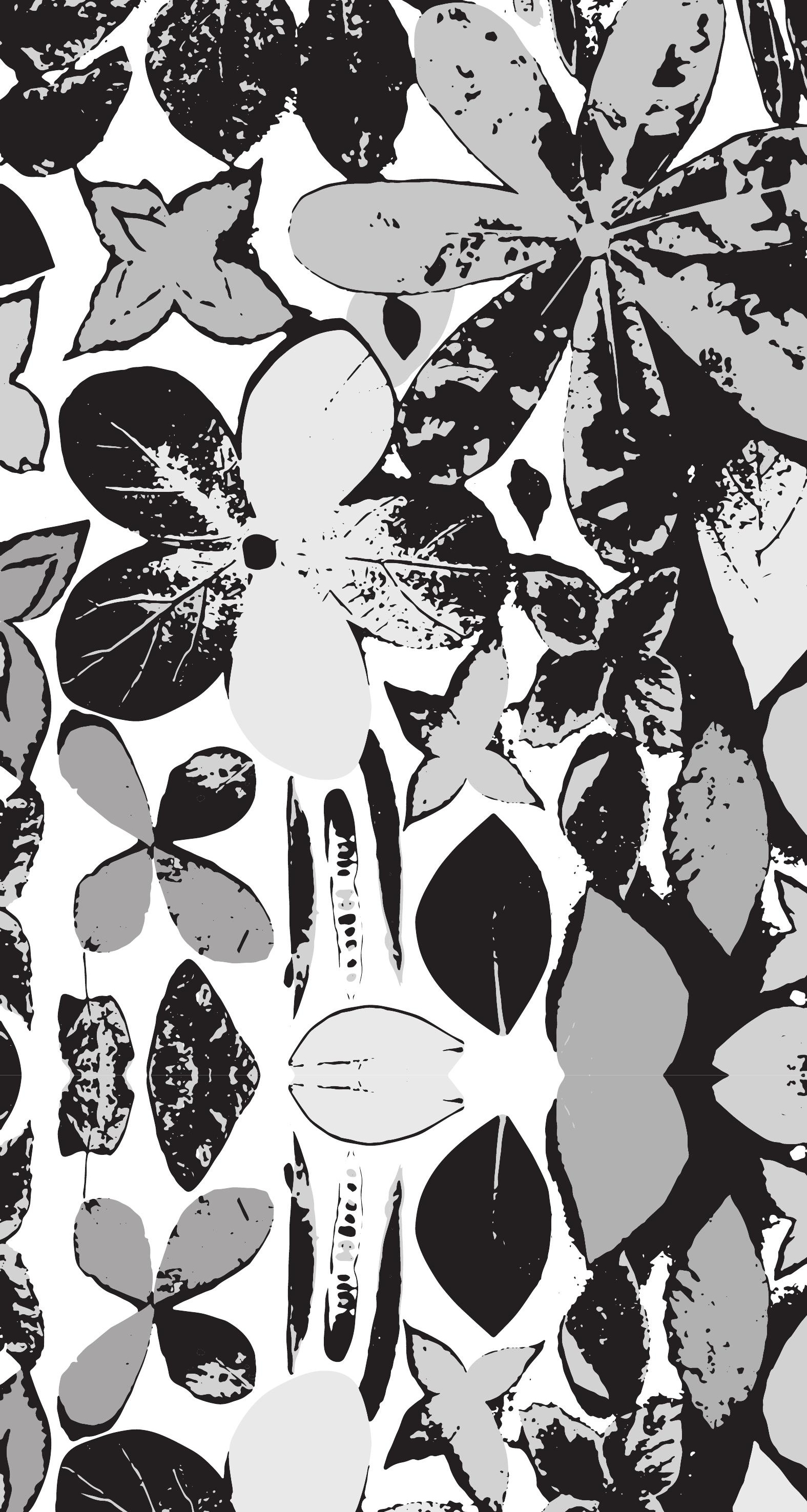




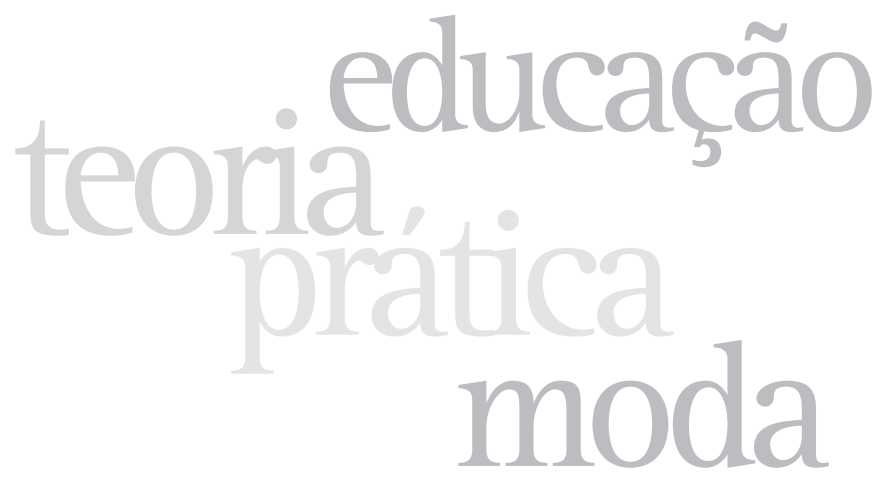

0 artigo de Mara Rúbia Sant'Anna, Das ementas de História da Moda ao conhecimento histórico, faz referência à pesquisa da autora realizada, entre 2011 e 2013, nos Estados de Santa Catarina e do Rio Grande do Sul, quando existiam 28 cursos de Design de Moda. A autora debruçou-se sobre 43 planos de ensino, o que representava mais da metade dos planos de ensino das disciplinas oferecidas nos cursos, o que permitiu a Mara Rúbia uma análise atenta das ementas dos planos que traziam em suas nomenclaturas o termo "história", tendo em vista mais que a existência da disciplina, o conteúdo por ela abordado, para avaliar principalmente 0 aspecto analítico.

Foi por essa proposição inovadora que, dentre os excelentes trabalhos apresentados no Grupo de Trabalho Educação: Teoria e Prática de Moda, organizado durante $010^{\circ}$ Colóquio de Moda, a pesquisa de Mara Rúbia se destacou pois o texto propicia a reflexão sobre o ensino de Moda, no tocante à visão e formação dos cursos de Design de Moda, bem como sobre a formação do profissional de moda, um desafio do ensino na contemporaneidade que a autora tão bem soube enfrentar.

Maria de Fátima Mattos

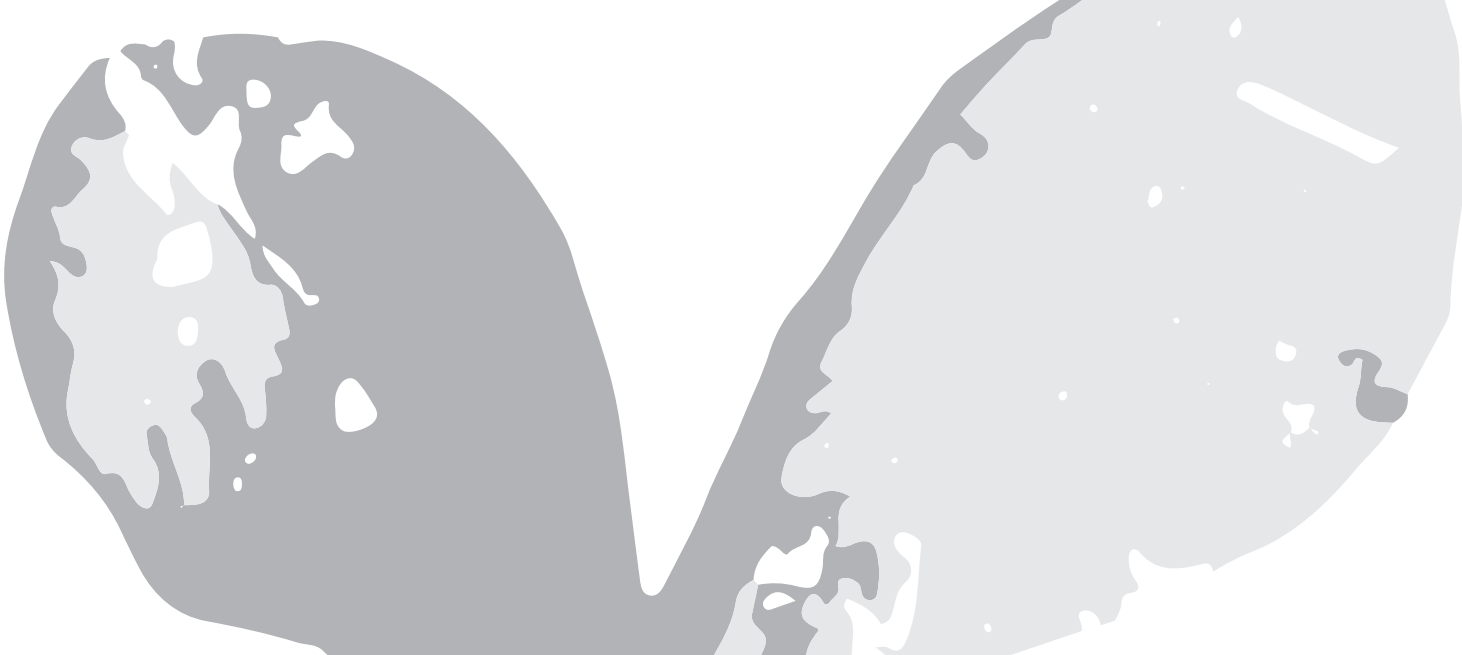


artigo $]$

[ MARA RÚBIA SANT'ANNA ]

Doutora em História pela Universidade Federal do Rio Grande do Sul (2005), professora efetiva do Departamento de Moda da Universidade do Estado de Santa Catarina. Autora dos livros Teoria de Moda (2007) e Elegância, beleza e poder (2014).

E-mail: sant.anna.udesc@gmail.com

\title{
Das ementas de História da Moda ao conhecimento histórico
}

\author{
From syllabuses of History \\ of Fashion to historical Knowledge
}

[resumo] Estudo do ementário das disciplinas de História da Moda oferecidas em Santa Catarina e Rio Grande do Sul, entre 2011 e 2013. Ênfase no aspecto analítico e nas implicações na formação do profissional de moda criativo e crítico. Dentre os diferentes aspectos a serem tratados neste estudo, será abordada a abrangência temática das ementas analisadas.

[abstract] Study menus the disciplines of Fashion History offered in Santa Catarina and Rio Grande do Sul, between 2011 and 2013. Emphasis on analytical aspects and implications in shaping the fashion creative and critical professionals. Among the different issues to be address in this study is treated on the thematic range of menus analyzed.

[keywords] menus the disciplines; fashion; history. 
0 projeto de pesquisa realizado junto ao curso de Moda da Universidade do Estado de Santa Catarina (Udesc), intitulado Ensino de História da Moda em Santa Catarina e Rio Grande do Sul: análise quantitativa e crítica do material bibliográfico utilizado, dos objetivos propostos e dos recursos audiovisuais explorados, teve como objetivo discutir o papel do ensino de história no curso de Design de Moda e sua importância na formação do profissional neste campo do conhecimento. A metodologia de desenvolvimento consistiu em: (1) contato com as instituições de ensino superior de Design de Moda dos Estados do Rio Grande do Sul e de Santa Catarina; (2) coleta e análise dos planos de ensino das disciplinas relacionadas à História; (3) visita às instituições com debate dos resultados obtidos; e (4) divulgação dos resultados com amplo debate e possibilidades dialógicas de encarar a realidade de pesquisa.

A pesquisa sobre o ensino de história em nível superior, em especial no curso de Moda, se justifica em vários aspectos, sobretudo pela raridade e ineditismo, pois se há muita produção acadêmica sobre o ensino de história no ensino fundamental e médio, quase nada é produzido sobre o ensino superior e menos ainda sobre o ensino de história oferecido para outras graduações que não seja a de História, propriamente dita. Os poucos estudos que existem com esse teor apontam para um ponto comum, apesar das diferenças entre os focos de pesquisa: o conhecimento histórico é fator relevante, que facilita a compreensão e desperta motivação no aluno, estimulando 0 entendimento das relações sociais de produção e poder que envolvem e culminam nas transformações sociais.

Cerri (2011) defende que o passado e as projeções do futuro são a matéria-prima para a criação, na medida em que uma consciência histórica ampliada e independente dos estereótipos dos sujeitos e das sociedades do passado, pasteurizados pelas mídias, permite ao sujeito social tornar-se mais crítico e inventor da realidade que o cerca. Essa perspectiva somente é possivel a partir da valorização das disciplinas ocupadas com o conhecimento histórico, o que, por sua vez, reflete no desenvolvimento da criatividade, visto que o conhecimento histórico compõe repertórios cognitivos e afetivos que servem ao processo da criação.

\section{Planos de ensino, denominação das disciplinas e carga horária}

Sobre os planos de ensino, é importante discutir, inicialmente, sua condição de documento e índice da realidade vivida em sala de aula. Como salienta José Cerchi Fusari:

[...] na prática docente atual, o planejamento tem-se reduzido à atividade em que o professor preenche e entrega à secretaria da escola um formulário, em muitos casos, os professores copiam ou fazem fotocópias do plano do ano anterior e o entregam [...] com a sensação de mais uma atividade burocrática cumprida. (FUSARI, 1988, p. 44)

Como documento finalizado, o planejamento ou o plano de ensino cumpre seu papel de registro da existência de uma disciplina e os conteúdos por ela desenvolvidos. Todavia, quando nele se observa incompletudes e incoerência, esse mesmo documento proporciona índices de que a atividade educacional não está planejada de forma eficiente e coletiva, pois suas lacunas descritivas apontam para falhas na comunicação, para as brechas deixadas para a improvisação, para a repetição de práticas já sancionadas a despeito das inovações tecnocientíficas que o conhecimento produziu nos últimos tempos. Por isso, cada plano de ensino observado é um documento fidedigno da proposta educacional adotada, na medida em que "[...] a ação consciente, competente e crítica do educador [é] que transforma a realidade, a partir das reflexões vivenciadas no planejamento e, consequentemente, do que foi proposto no plano de ensino", como afirma Fusari (1988, p. 46).

Segundo Haydt (2010), o plano de ensino é resultado do processo mental do planejamento, é esboço das conclusões resultantes do planejamento mental, comumente assumindo a forma de documento escrito. Moretto $(2007$, p. 10) acredita que 
alguns componentes fundamentais devem ser considerados na elaboração do plano: conhecer sua própria personalidade enquanto professor, conhecer seus alunos e suas características psicossociais e cognitivas, ser adequado à disciplina em questão.

Tendo em vista esses apontamentos teóricos, os planos de ensino foram tratados estatisticamente, compondo diversos gráficos e quadros, os quais deram conta dos 27 planos coletados em Santa Catarina e dos 16 coletados no Rio Grande do Sul. A soma de 43 planos de ensino analisados permitiu análises conclusivas, já que se ultrapassou 50\% do total absoluto de planos disponíveis nos dois Estados da Federação, que é de 72 disciplinas oferecidas em história nos 28 cursos de Design de Moda existentes em 2011.

Dentre todos os itens que podem aparecer num plano de ensino, o formato ideal para o ensino superior contempla: ementa, carga horária, objetivos gerais e especificos, metodologia, conteúdo, bibliografia básica e complementar. Outros textos produzidos ao longo da pesquisa discutiram diversos desses itens, porém, neste texto, analisa-se o item "ementa".

A ementa é um resumo do conteúdo a ser ministrado em uma disciplina que deve ter aprovação do colegiado do curso e é item obrigatório na composição das grades curriculares do ensino superior, sendo avaliada pelos responsáveis pelo reconhecimento e pelas consequentes aprovações dos cursos superiores no Brasil. Esse item não pode ser modificado. Ocasionalmente, o professor responsável pela disciplina ou outro interessado pode propor alterações à ementa, todavia, tais sugestões devem ser submetidas ao colegiado e às demais instâncias universitárias para aprovação. Os manuais didáticos também informam que a ementa deve ter consonância com 0 plano pedagógico do curso e servirá de embasamento, posteriormente, para a criação do plano de ensino (objetivos, conteúdos, metodologias, bibliografias etc.).

Uma ementa bem definida e planejada, de acordo com os objetivos do curso, orienta o professor na hora de definir os objetivos gerais e específicos da disciplina, os conteúdos e temas de forma mais individual, as metodologias e avaliações mais adequadas e a bibliografia mais coerente aos assuntos propostos, facilitando 0 planejamento individual de cada aula e a produção do documento plano de ensino, conduzindo, assim, o professor e o aluno para um ensino de qualidade.

Dentre a proposta metodológica foi realizada a análise dos planos de ensino das disciplinas com nomenclatura "história" nos cursos de Moda em Santa Catarina e Rio Grande do Sul, e a partir dela o estudo das ementas dos 43 planos de ensino coletados. Esse estudo contemplou, de início, um obstáculo à sistematização dos dados, pois há uma variedade muito grande de denominações das disciplinas oferecidas com o termo "história".

São, grosso modo, 13 variantes de denominação, cuja diversidade aponta para três tipos de concentração: moda, arte e design. Quanto às disciplinas relacionadas à moda, constando em sua denominação o termo e tendo o foco na história do sistema de moda, encontram-se 18 disciplinas; se considerarmos a indumentária, esse número sobe para 25, porém, quanto às que contemplam o termo "arte", tem-se 16 disciplinas e, por último, considerando a denominação "história do design", esta aparece apenas em duas disciplinas, mas quando combinada com outros termos, se faz presente em outras nove, o que somam 11 disciplinas. Portanto, considerando o aspecto da terminologia empregada, mesmo que grande parte das Instituições de Ensino Superior adote como nome do curso "Design de Moda", o que prevalece é o enfoque na história da moda, às vezes atrelada ao estudo da arte, do design ou da indumentária e até mesmo da tecnologia e da estética.

Talvez isso se deva à tradição bibliográfica e de estudo dos professores que atuam nas disciplinas e que formularam as grades curriculares. Grande parte provém de cursos de bacharelado em Moda ou de outros, e não necessariamente do Design. Igualmente, em levantamento feito por essa mesma pesquisa, entre os dez títulos mais 
citados nas bibliografias básicas, encontram-se livros voltados à história do vestuário e da moda, como mostrado no quadro abaixo:

Figura 1: Bibliografia básica presente nos planos de ensino coletados com frequência de presença discriminada

\begin{tabular}{|c|c|c|c|}
\hline Est. & Título & Autor & Repetição \\
\hline \multirow{10}{*}{ SC } & Império do efêmero & Gilles Lipovetsky & 17 \\
\hline & A roupa e a moda & James Laver & 16 \\
\hline & História do vestuário & Karl Kohler & 13 \\
\hline & História da moda: uma narrativa & João Braga & 11 \\
\hline & História da arte & E. H. Gombrich & 11 \\
\hline & Moda do século & François Baudot & 8 \\
\hline & Arte comentada & Carol Strickland & 8 \\
\hline & Uma introdução à história do design & Rafael Cardoso & 8 \\
\hline & História da vida privada & Philippe Ariès & 6 \\
\hline & O design brasileiro antes do design & Rafael Cardoso & 5 \\
\hline \multirow{10}{*}{ RS } & A roupa e a moda & James Laver & 7 \\
\hline & História do vestuário & Karl Kohler & 5 \\
\hline & História da moda: uma narrativa & João Braga & 4 \\
\hline & História da arte & E. H. Gombrich & 4 \\
\hline & Moda do século & François Baudot & 4 \\
\hline & História do vestuário no Ocidente & François Boucher & 4 \\
\hline & Estilos, escolas e movimentos & Amy Dempsey & 4 \\
\hline & História da moda do século XX & Gertrud Lehnert & 4 \\
\hline & Império do efêmero & Gilles Lipovetsky & 3 \\
\hline & A moda do século XX & $\begin{array}{l}\text { Valerie Mendes e } \\
\text { Amy de La Haye }\end{array}$ & 3 \\
\hline
\end{tabular}

Fonte: Coleta de dados na fonte e tabulação pelas bolsistas de IC, 2013.

Como é observável, apenas em Santa Catarina encontram-se títulos que tratam da história do Design, no caso, os livros de Rafael Cardoso. Para o Rio Grande do Sul, nenhum título está vinculado a essa área de conhecimento entre os dez mais citados.

Ainda quando se fala em ementa, também se deve ponderar a carga horária disponivel para cada disciplina, pois ementas muito vastas precisam, obviamente, de carga horária estendida, o que não é sempre equilibrado no caso das disciplinas de História oferecidas para o bacharelado em Moda. 
Figura 2: Carga horária das disciplinas

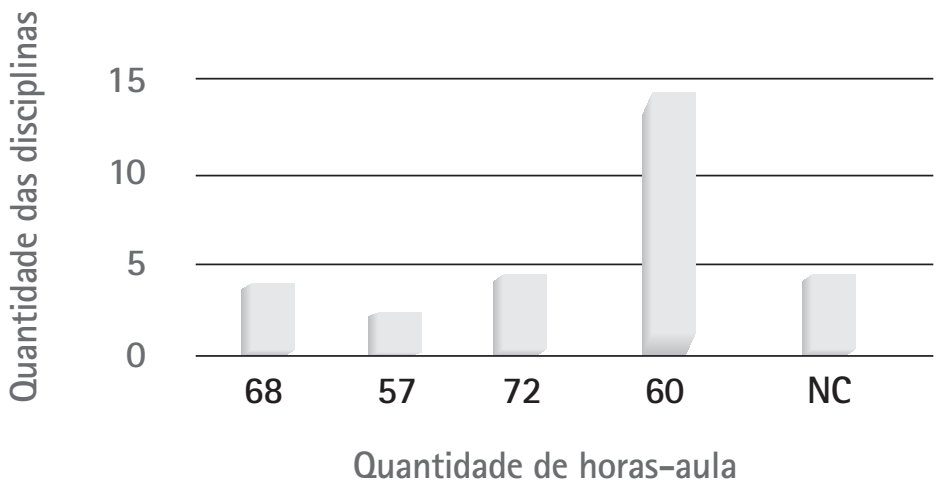

Fonte: Coleta de dados na fonte e tabulação pelas bolsistas de IC, 2013.

Portanto, a carga horária proposta para as disciplinas de história, independentemente de serem mais ou menos abrangente em seus conteúdos, é de quatro créditos e estão, em sua maioria, sendo ofertadas na primeira e segunda fase do curso, como já discutido em outro texto (SANT'ANNA, 2012), e ficando, em sua maioria, com quatro ou oito créditos ao longo de toda a grade curricular.

\section{Ementas em análise}

Como repertório dos assuntos a serem abordados numa disciplina, as ementas de história oferecem alguns campos de análise próprios, relacionados a uma intensa discussão sobre a metodologia do ensino de história. Na pesquisa realizada, foi estudada a denominação da disciplina, a abrangência temporal, espacial e temática e, ainda, a carga horária da disciplina, como visto acima. Este texto se restringe à exposição dos resultados relativos à temática contemplada nas ementas'.

Numa visão mais tradicional, o que impera na discriminação dos assuntos a serem tratados por uma disciplina de história são os períodos históricos e os grandes fatos, com seus heróis e narrações detalhadas. Esse tipo de ementário prevaleceu em manuais de história voltados para o ensino fundamental e médio até os anos 1980, no Brasil (FONSECA, 2011).

0 ementário firmado em períodos históricos foi, num primeiro momento, reformulado a favor de uma história firmada nos princípios do materialismo histórico. Foi no fim dos anos 1980 e começo dos 1990 que uma mudança mais intensa ocorreu à medida que uma proposta historiográfica atenta às mentalidades e sensibilidades sociais foi se impondo no modelo da "Nova História". Dessa maneira, os períodos históricos foram perdendo lugar para ementas que privilegiavam temas muitas vezes trabalhados transversalmente, abandonando a narrativa cronológica e linear do passado.

Por isso, ao se observar uma ementa, com sua seleção de temas e/ou períodos históricos, é possivel deduzir a visão historiográfica que nutriu sua definição. Também permite analisar quais seriam as abrangências temporal e espacial que a disciplina pretende abordar e, consequentemente, as possibilidades de discussão crítica, tendo em vista a carga horária e a bibliografia recomendada.

Estudando os 43 planos de ensino, observa-se que vários temas e períodos predominam. Duas disciplinas trabalham exclusivamente períodos e dez trabalham com temas, enquanto 27 citam períodos históricos e temas. 
Figura 3: Composição da ementa por períodos e temas

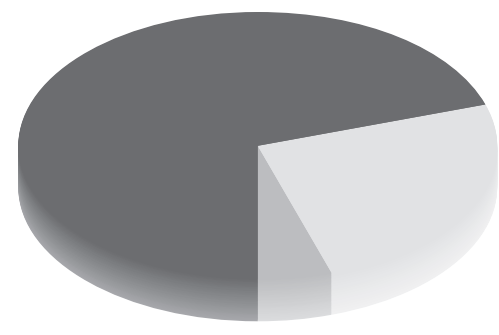
período
temas
períodos e temas

Fonte: Coleta de dados e tabulação pelas bolsistas de IC, 2013.

De todos os planos de ensino coletados, quatro não apresentam ementa.

No quadro abaixo, podem ser observados os temas e suas frequências discriminados:

Figura 4: Temas selecionados das ementas e frequência

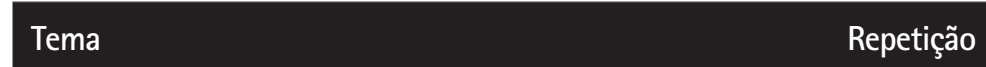

\begin{tabular}{|l|l|}
\hline Arte & 18 \\
\hline Vestuário & 18 \\
\hline Moda & 9 \\
\hline Design & 8 \\
\hline Condições socioculturais & 5 \\
\hline Revolução Industrial & 5 \\
\hline Brasil & 4 \\
\hline Renascimento & 3 \\
\hline Alta-costura & 2 \\
\hline Povos da Antiguidade & 2 \\
\hline Grandes guerras & 2 \\
\hline Referências estéticas & 2 \\
\hline Tecnologia & 2 \\
\hline Sociedade burguesa & 2 \\
\hline Individualismo & 1 \\
\hline Aparência & 1 \\
\hline Poder & 1 \\
\hline Sistema de moda & 1 \\
\hline Identidade & 1 \\
\hline Belle Époque & 1 \\
\hline Processos criativos & 1 \\
\hline Pós-modernidade & 1 \\
\hline
\end{tabular}


Para compor a Figura 4, foram considerados os termos utilizados na composição das ementas, sendo os similares agrupados por afinidade a outros mais recorrentes.

Como se observa acima, a abrangência temática é bastante variada, contemplando diferentes assuntos que perpassam a longa temporalidade trabalhada. Contudo se destacam: arte, com 18 repetições; vestuário, com 18; moda, com 9; design, com 8; condições socioculturais e Revolução Industrial, com 5; e Brasil, com 4, citando as mais recorrentes.

Essa frequência coincide com a nomenclatura das disciplinas, o que é facilmente justificado. Por outro lado, evidencia a dificuldade em propor temas transversais que pudessem desenvolver abordagens mais específicas, levando o estudante a um estudo mais aprofundado sobre um tema em épocas e sociedades distintas. 0 caso de "condições socioculturais" é consolador, pois, como tema, ele define um diapasão de abordagem de diferentes sociedades, mesmo que ainda seja uma abordagem extremamente ampla, o que exigiria muito tempo para a realização de estudo.

Os casos de "processos criativos", "individualismo", "aparência", "poder", "sistema de moda" e "identidade" são temas que apareceram com baixa frequência e que se caracterizam como temáticas que poderiam ser abordadas em diferentes épocas e sociedades, permitindo uma discussão mais apurada da moda em seu processo histórico. Eles convocariam, em seus tratamentos transversais, pesquisa mais intensa, discussões mais criticas, que dariam à história possibilidade de contribuição mais rica na formação do profissional de moda criativo e crítico. Inversamente, há uma excessiva preocupação num relato factual do passado dos hábitos de vestir, ao menos no momento da composição das ementas que servem à análise. Assim também, por exemplo, a temática "corpo", não apresentada, indica uma falta irreparável, tendo em vista a intensa relação entre corpo, vestuário e moda, bastante discutida por diversos autores e colocada como uma questão-chave da moda contemporânea em seus anseios de lidar mais com os desejos do que com os consumos diretos do vestuário.

As discussões são inúmeras e todas sugerem que os professores de história da moda devem manter um estado de alerta e crítica diante das ementas que têm em mãos para trabalhar.

Resumidamente, pode-se afirmar que a análise das ementas presentes nos planos de ensino demonstra que:

- A disciplina, apesar da carga horária pequena, é encarregada de dar conta de grande quantidade de conteúdo, percorrendo grandes períodos históricos, sociedades e temas;

- Mesmo sendo a moda um fenômeno mundial e o mercado de moda ter, hoje, um olhar muito atento para as culturas locais e especialmente para as culturas distintas da ocidental, o ensino de história da moda privilegia a história ocidental, centrada numa visão universalista e descontextualizada;

- Apesar dos avanços historiográficos e da prevalência da "Nova História", que dá ênfase para a história temática, abordada transversalmente, desde o fim do século $X X$, no caso dos planos de ensino analisados, os ementários das disciplinas de história do ensino superior em Design de Moda ainda se organizam em torno dos períodos históricos tradicionais, ocupam-se de eventos marcantes, se desenvolvem de forma cronológica e pouco valorizam temas que articulem as discussões entre moda e sociedade, como no caso de identidade, individualismo, corpo etc.

\section{Considerações finais}

Se por um lado há de se ressaltar que as ementas, por mais bem analisadas que sejam, não demonstram a realidade da sala de aula e as maneiras peculiares que cada professor tem de arquitetar as disciplinas que ministra, por outro, se sabe que as 
propostas curriculares e as consequentes ementas que as compõem expressam uma visão de mundo, a concepção de formação dos profissionais de moda que o grupo de professores, autores do curso, realizaram e, por essa ótica, pode-se afirmar que as disciplinas de história foram formuladas, em sua maioria, muito mais pela bagagem pessoal de ex-alunos do ensino fundamental e médio de história e experiências docentes anteriores do que a partir de um amplo debate que cotejasse tendências historiográficas e habilidades cognitivas desejadas por meio do conhecimento histórico.

Concluindo, o ensino de história para o curso superior em Moda pode contribuir significativamente para a formação do designer do vestuário, mas para tanto é necessário maior atenção às discussões relativas à formulação das grades curriculares e às formações acadêmicas exigidas dos professores que irão atuar nas disciplinas de história. 0 modelo existente, pela análise realizada, consiste em compactar o máximo de assunto em poucas disciplinas, com cargas horárias pequenas, o que remete a outra problemática instigante, qual seja, a da preponderância de disciplinas práticas em detrimento das teóricas em cursos como os de Moda. Todavia, isso já seria outra discussão que não cabe mais aqui realizar.

[1] Ver Anais do $4^{\circ}$ ENPModa, artigo Ensino de História da Moda: ementas adotadas, que apresenta os demais aspectos do estudo relativo às ementas.

\section{REFERÊNCIAS}

BAHIA, Sara. Criatividade e universidade entrecruzam-se? Revista Eletrônica Sísifo, n. 7, set.-dez. 2008, p. 51-61. Disponivel em: <http://sisifo.fpce.ul.pt/pdfs/sisifo7D5PT.pdf . Acesso em: 12 mar. 2013.

CABRAL, Maria Helena. História e medicina: a herança arcaica de um paradigma. Revista Eletrônica História, Ciências, Saúde. Rio de Janeiro, nov. 1999-fev. 2000, p. 551-575. Disponivel em: <http://www. scielo.br/scielo.php?script=sci_arttextctpid=S0104-59702000000400004>. Acesso em: 14 maio 2013.

CERRI, Luis Fernando. Ensino de história e consciência histórica: implicações didáticas de uma discussão contemporânea. Rio de Janeiro: FGV, 2011.

FERREIRA, Terezinha Francelino. A disciplina história da matemática: um estudo sobre as concepções do professor do ensino superior. São Paulo, 2005. Dissertação (Mestrado em Matemática) - Pontificia Universidade Católica, São Paulo. Disponivel em: <http://www.pucsp.br/pos/edmat/mp/dissertacao/ terezinha_francelino_ferreira.pdf. Acesso em: 28 abr. 2013.

FONSECA, Thais Nivia de Lima e. História e ensino de história. Belo Horizonte: Autêntica, 2011.

FUSARI, José Cerchi. 0 papel do planejamento na formação do educador. São Paulo: SEE/CENP, 1988.

HAYDT, Regina Célia Cazaux. Curso de didática geral. São Paulo: Ática, 2006.

LEAL, Regina Barros. Planejamento de ensino: peculiaridades significativas. Revista Eletrônica lberoamericana de Educación. v. 37, n. 3, 2005. Disponível em: <http://www.rieoei.org/deloslectores/1106Barros.pdf>. Acesso em: 12 jul. 2012.

MORETTO, Vasco Pedro. Planejamento: planejando a educação para o desenvolvimento de competências. Petrópolis: Vozes, 2007

OKI, Maria da Conceição Marinho; MORADILLO, Edílson Fortuna. 0 ensino da História da Química: contribuindo para a compreensão da natureza da ciência. Revista Ciência e Educação. v. 14, n. 1, 2008, p. 67-88. Disponivel em: <http://www.scielo.br/pdf/ciedu/v14n1/05.pdf>. Acesso em: 30 jun. 2013.

PADILHA, Paulo Roberto. Planejamento dialógico: como construir o projeto político-pedagógico da escola. São Paulo: Cortez, 2001.

SANT'ANNA, Mara Rúbia. História da Moda: entre a informação e a crítica, possibilidades de uma prática de ensino com qualidade. In: VANDRESEN, Monique; SANTANNA, Mara Rúbia. Moda, Comunicação e Universidade. Série Modapalavra, v. 7. Florianópolis: Udesc, 2012, p. 189-20. $\overline{\text { UDESC, }} 2014$.

Ensino de história da moda: ementas adotadas. In: Anais do $4^{\circ}$ ENPModa. Florianópolis:

Ementas de história: o ensino de moda em discussão. In: PULS, Lourdes Maria. Moda,

Sociedade e Tecnologia. Série Modapalavra, v. 9. Florianópolis: Udesc, 2014. 